\title{
THE MOTION OF COMET ENCKE-BACKLUND OVER 1901-1970
}

\author{
N. A. BOKHAN and Yu. A. CHERNETENKO \\ Institute of Theoretical Astronomy, Leningrad, U.S.S.R.
}

The investigation of the 22 apparitions of Comet Encke-Backlund for the time interval 1901-70 was carried out. The integration of equations of motion was performed using the technique devised by Kazimirchak-Polonskaya with automatic step choice, taking into account the perturbations from nine planets (Mercury-Pluto) as well as nongravitational effects.

The observations made before and after the perihelion passage are presented with sufficient accuracy. The existence of a continuous secular acceleration in the cometary motion is confirmed and the secular variation of the eccentricity is shown to be a function of time. 